\title{
Factors associated with shunt-dependent hydrocephalus after decompressive craniectomy for traumatic brain injury
}

\author{
Aditya Vedantam, MD, ${ }^{1}$ Jose-Miguel Yamal, PhD, ${ }^{2}$ Hyunsoo Hwang, MS, ${ }^{2}$ \\ Claudia S. Robertson, MD, ${ }^{1}$ and Shankar P. Gopinath, MD1 \\ 1Department of Neurosurgery, Baylor College of Medicine; and 2Department of Biostatistics, University of Texas School of Public \\ Health, Houston, Texas
}

OBJECTIVE Posttraumatic hydrocephalus (PTH) affects $11.9 \%-36 \%$ of patients undergoing decompressive craniectomy (DC) and is an important cause of morbidity after traumatic brain injury (TBI). Early diagnosis and treatment of PTH can prevent further neurological compromise in patients who are recovering from TBI. There is limited data on predictors of shunting for PTH after DC for TBI.

METHODS Prospectively collected data from the erythropoietin severe TBI randomized controlled trial were studied. Demographic, clinical, and imaging data were analyzed for enrolled patients who underwent a DC. All head CT scans during admission were reviewed and assessed for PTH by the Gudeman criteria or the modified Frontal Horn Index $\geq$ $33 \%$. The presence of subdural hygromas was categorized as unilateral/bilateral hemispheric or interhemispheric. Using L1-regularized logistic regression to select variables, a multiple logistic regression model was created with ventriculoperitoneal shunting as the binary outcome. Statistical significance was set at $p<0.05$.

RESULTS A total of 60 patients who underwent DC were studied. Fifteen patients $(25 \%)$ underwent placement of a ventriculoperitoneal shunt for PTH. The majority of patients underwent unilateral decompressive hemicraniectomy $(n=$ 46, 77\%). Seven patients (12\%) underwent bifrontal DC. Unilateral and bilateral hemispheric hygromas were noted in $31(52 \%)$ and $7(11 \%)$ patients, respectively. Interhemispheric hygromas were observed in 19 patients (32\%). The mean duration from injury to first CT scan showing hemispheric subdural hygroma and interhemispheric hygroma was $7.9 \pm 6.5$ days and $14.9 \pm 11.7$ days, respectively. The median duration from injury to shunt placement was 43.7 days. Multivariate analysis showed that the presence of interhemispheric hygroma (OR 63.6, $p=0.001)$ and younger age $(\mathrm{OR} 0.78, p=$ 0.009 ) were significantly associated with the need for a shunt after DC.

CONCLUSIONS The presence of interhemispheric subdural hygromas and younger age were associated with shuntdependent hydrocephalus after DC in patients with severe TBI.

https://thejns.org/doi/abs/10.3171/2017.1.JNS162721

KEY WORDS posttraumatic hydrocephalus; shunt-dependent hydrocephalus; decompressive craniectomy; severe traumatic brain injury

$\mathrm{P}$ OSTTRAUMATIC hydrocephalus (PTH) affects $11.9 \%-$ $36 \%$ of patients undergoing decompressive craniectomy (DC) after traumatic brain injury (TBI), ${ }^{2,47,14}$ Hydrocephalus often develops more than a month after a patient undergoes $\mathrm{DC}^{21}$ and can be associated with poorer outcomes. ${ }^{17}$ Early diagnosis and treatment of PTH can prevent further neurological compromise in patients who are recovering from TBI.
The diagnosis of hydrocephalus in patients with large craniectomy defects remains a challenge. Ventriculomegaly after DC is not always indicative of hydrocephalus requiring treatment. ${ }^{17}$ The presence of subdural CSF collections, although suggestive of abnormal CSF circulation, may not be associated with clinical symptoms of hydrocephalus. ${ }^{1,24}$ It is therefore unclear if certain imaging features are more closely associated with the need for a ventriculoperitoneal

ABBREVIATIONS DC = decompressive craniectomy; GCS = Glasgow Coma Scale; IVH = intraventricular hemorrhage; PTH = posttraumatic hydrocephalus; SAH = subarachnoid hemorrhage; $\mathrm{TBI}=$ traumatic brain injury; VPS = ventriculoperitoneal shunt.

SUBMITTED October 29, 2016. ACCEPTED January 5, 2017.

INCLUDE WHEN CITING Published online June 16, 2017; DOI: 10.3171/2017.1.JNS162721. 
shunt (VPS) in PTH. The aim of this study was to identify factors associated with shunt-dependent hydrocephalus in patients undergoing DC for TBI.

\section{Methods \\ Study Sample}

We analyzed prospectively collected data from a randomized controlled trial studying the effects of erythropoietin and blood transfusions on recovery after severe TBI (Epo Severe TBI trial; clinicaltrials.gov no. NCT00313716). For the present study, we selected enrolled patients who had undergone a DC after admission. Details of the study design and results of the randomized trial have been published previously. ${ }^{20}$ The study was approved by the IRB at each participating institution. For the randomized controlled trial, a legally authorized representative provided written informed consent during the first year of the study, and after this the study was approved for and conducted under the conditions of the Exception From Informed Consent for Emergency Research. Patients with a closed head injury and unable to follow commands after resuscitation were enrolled within 6 hours of injury at a Level I trauma center. Patients with a Glasgow Coma Scale (GCS) score of 3 with fixed and dilated pupils, penetrating trauma, life-threatening systemic injuries, pregnancy, and severe preexisting disease were excluded. All patients were managed in an intensive care unit according to the Guidelines for the Management of Severe Head Injury (see Supplement 1 from Robertson et al. ${ }^{20}$ ). The study was conducted from May 2006 to August 2012.

\section{Surgery Characteristics}

Decompressive surgery was performed at admission or at a delayed time point due to the presence of midline shift, contusions, cerebral edema, or intractable intracranial pressure. Unilateral decompressive hemicraniectomies of at least $15 \mathrm{~cm}$ in diameter were performed with the medial limit at least $2.5 \mathrm{~cm}$ lateral to the midline. Bifrontal DCs were performed with the posterior limit at the coronal suture. All cases underwent expansive duraplasty with an allograft. VPS placement was performed for a combination of clinical signs and radiographic features. For some patients, no definite change in clinical examination was noted, but considerable enlargement of ventricles was noted on serial head CT scans.

\section{Data Collection}

Demographic, clinical, and imaging data at admission, during the hospital stay, and at follow-up were used for this study. All CT scans after the DC were reviewed and assessed for PTH using the criteria described by Gudeman et al. ${ }^{5}$ (lateral and third ventricular enlargement, periventricular lucencies) or the modified Frontal Horn Index $\geq 33 \%$ (Fig. 1). ${ }^{9}$ The presence of subdural hygromas was recorded according to location: ipsilateral, contralateral, bilateral, and interhemispheric (Fig. 2). In patients with bifrontal or bilateral fronto-temporo-parietal craniectomies, the hygroma was categorized by the side of the larger craniectomy defect.

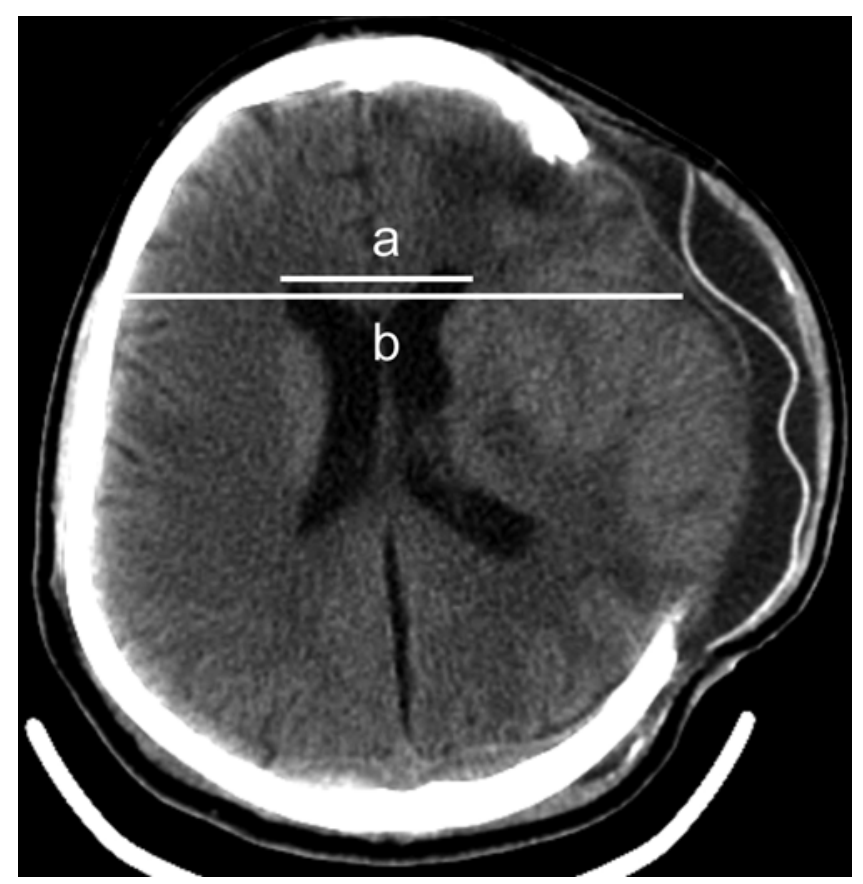

FIG. 1. Measurement of the modified Frontal Horn Index $(=a / b)$ on postoperative axial head CT scan after left fronto-temporo-parietal DC.

\section{Statistical Analysis}

Statistical analysis was performed using the $\mathrm{R}$ program (version 2.13.1, R Foundation for Statistical Computing). Univariate analysis was performed by comparing patients who underwent VPS placement and patients who did not require a VPS. Continuous variables were analyzed using a Welch 2-sample t-test and categorical variables were analyzed using the Fisher exact test. Using L1-regularized logistic regression to select variables, a multiple logistic regression model was created with ventriculoperitoneal shunting as the binary outcome. Statistical significance was set at $\mathrm{p}<0.05$.

\section{Results}

A total of 60 patients who underwent DC were studied. Fifteen patients (25\%) underwent placement of a VPS for PTH. A fixed medium-pressure shunt valve was inserted in 8 patients (53.3\%), and a programmable valve was inserted in 4 patients (26.7\%). Details of the shunt valve were not available for 3 patients. Five patients required subsequent shunt revisions.

Baseline demographic, clinical, and imaging data are shown in Table 1 . The majority of patients were male (86.7\%), and patients undergoing a VPS placement after DC were significantly younger than those who did not undergo VPS insertion $(\mathrm{p}<0.001)$. The majority of patients underwent DC within 24 hours of the injury (88.3\%). Decompressive surgery was performed at a median of 2 hours after injury (range 1-222 hours). Data on indications for shunting were available for 12 of 15 patients who underwent shunt placement. In 6 patients, only radiological features of increased ventricle size were noted prior 

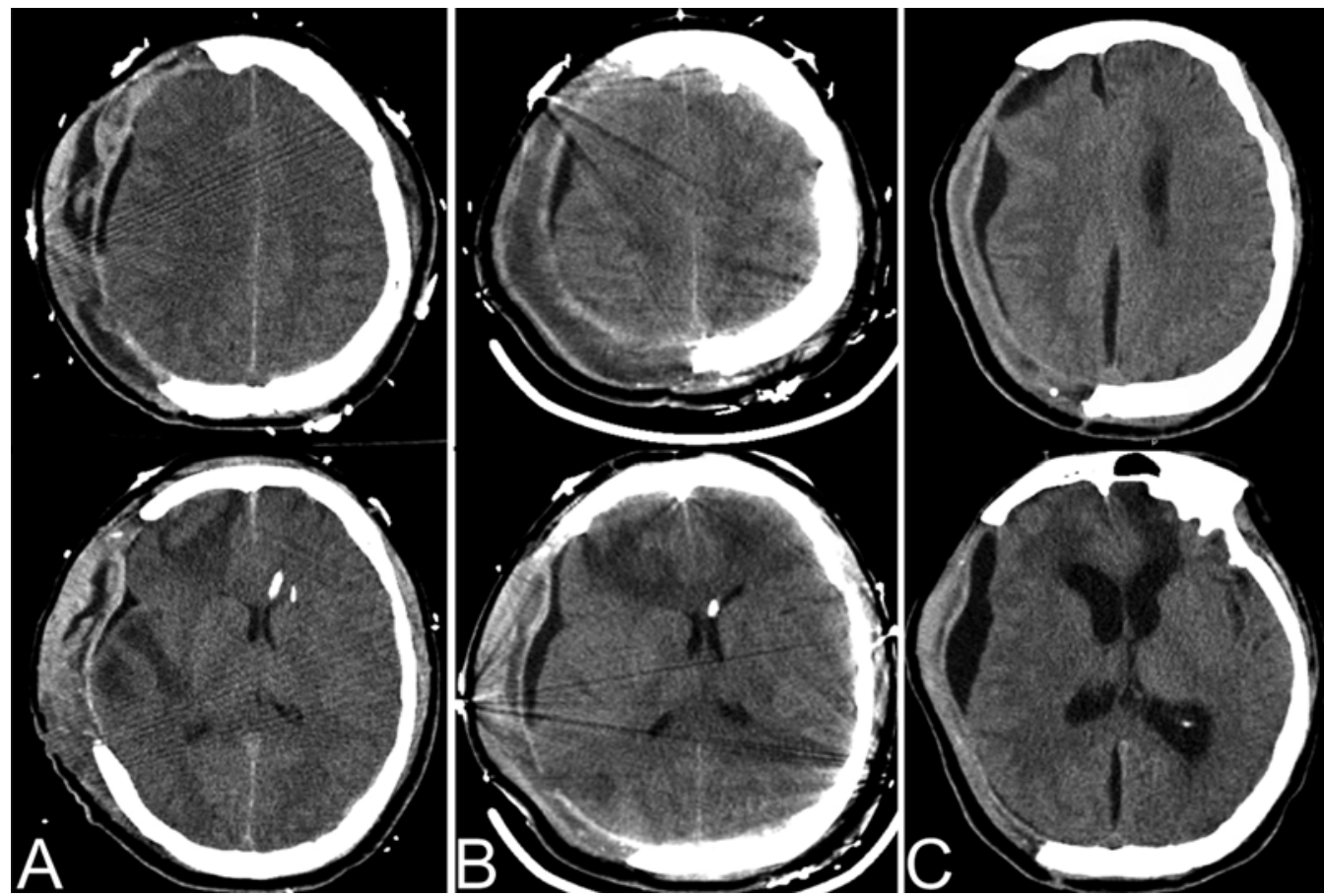

FIG. 2. Serial axial head CT scans showing progressive development of right hemispheric and interhemispheric subdural hygromas after right fronto-temporo-parietal DC for TBI. This patient underwent VPS placement for PTH. The duration from injury to $\mathrm{CT}$ scanning was Day 7 (A), Day $11(\mathbf{B})$, and Day 38 (C).

to shunt insertion. In 6 patients, a combination of clinical signs and increased ventricle size was observed. Clinical signs included increasing size of pseudomeningocele on the side of the craniectomy flap $(\mathrm{n}=3)$ and worsened neurological examination $(n=3)$. There was no significant association between the transfusion thresholds $(\mathrm{p}=0.14)$ or erythropoietin administration $(\mathrm{p}=0.23)$ and the need for shunting. Outcome data for this cohort are presented in Table 2. There were 14 deaths in the cohort at a median duration of 15 days (range 3.4-180 days).

CT showed evidence of PTH in $43.3 \%$ of patients. The median size of interhemispheric hygromas was $6.93 \mathrm{~mm}$ (range 2.96-10.76 mm, $\mathrm{n}=18$ ). There was no significant difference in median size of interhemispheric hygromas between patients who underwent VP shunt insertion and those who did not (6.91 vs $6.93 \mathrm{~mm}, \mathrm{p}=0.96$, MannWhitney U-test). The mean duration from injury to first CT scan showing a modified Frontal Horn Index $\geq 33.3 \%$ was $16.4 \pm 15.6$ days. The mean times from injury to first CT scan showing hemispheric subdural hygroma and interhemispheric hygroma were $7.9 \pm 6.5$ days and $14.9 \pm$ 11.7 days, respectively. The median duration from injury to shunt placement was 43.7 days (range 23.5-199 days). For patients who underwent a VPS insertion, cranioplasty was performed during the same admission in 10 patients at a median duration of 33.5 days (range 21.7-55.2 days). Cranioplasty was performed before insertion of a VPS in 8 patients (median duration 10 days, range 3-26.4 days) and simultaneously with shunt placement in 2 patients.

Multivariate analysis showed that the presence of interhemispheric hygroma $(\mathrm{p}=0.001)$ and younger age $(\mathrm{p}$ $=0.009$ ) were significantly associated with the need for a VPS after DC (Table 3).

\section{Discussion}

The present study found PTH in $43.3 \%$ of patients after DC for TBI and 25\% of all patients required a VPS. Younger patients and patients with an interhemispheric hygroma on postoperative CT were more likely to undergo VPS placement after DC.

Subdural hygromas on CT imaging after DC have been reported in $16 \%-50 \%$ of patients. ${ }^{1,6,8,10,24}$ These hygromas have been thought to reflect impaired CSF circulation, although many hemispheric subdural hygromas show resolution on serial imaging. ${ }^{1}$ In this study, only $37.8 \%$ of patients with hemispheric subdural hygromas required a VPS. Conversely, more than $50 \%$ of patients with an interhemispheric hygroma underwent placement of a VPS. CT first showed hemispheric subdural hygromas at an average of 7 days prior to interhemispheric subdural hygromas. It is possible that a greater derangement in CSF dynamics is needed to create an interhemispheric hygroma as compared to a hemispheric subdural hygroma. Kaen et al. ${ }^{12}$ proposed that large interhemispheric hygromas represent the subacute hydrodynamic phase of cerebral swelling after DC, which may explain the delayed presentation of these CSF collections. The appearance of interhemispheric hygromas in the 2 nd or 3 rd week after a DC is a potential predictor for the development of symptomatic hydrocephalus.

A number of factors have been shown to be associated with PTH including low initial GCS score, ${ }^{7}$ traumatic subarachnoid hemorrhage (SAH), and intraventricular hemorrhage (IVH). ${ }^{22}$ Some authors have shown that traumatic $\mathrm{SAH}$ and IVH are not associated with $\mathrm{PTH},{ }^{12,18}$ and we did not find these factors to be predictive of the need for 
TABLE 1. Demographic, clinical, and imaging data for 60 patients undergoing DC after severe TBI

\begin{tabular}{|c|c|c|c|c|}
\hline \multirow[b]{2}{*}{ Variable } & \multirow[b]{2}{*}{ Total } & \multicolumn{2}{|c|}{ VPS Placement After DC } & \multirow{2}{*}{$\begin{array}{c}p \\
\text { Value }\end{array}$} \\
\hline & & Yes & No & \\
\hline No. of patients & 60 & 15 & 45 & \\
\hline Mean age in yrs (SD) & $34.08(11.76)$ & $26.6(7.1)$ & $36.58(12)$ & $<0.001$ \\
\hline $\operatorname{Sex}(\%)$ & & & & 0.40 \\
\hline Male & $52(87)$ & $12(80)$ & $40(89)$ & \\
\hline Female & $8(13)$ & $3(20)$ & $5(11)$ & \\
\hline Mean GCS score* (SD) & $6.2(3.08)$ & $5.4(2.5)$ & $6.5(3.23)$ & 0.18 \\
\hline SAH (\%) & & & & 0.04 \\
\hline Yes & $51(85)$ & $10(67)$ & $41(91)$ & \\
\hline No & $9(15)$ & $5(33)$ & $4(9)$ & \\
\hline IVH (\%) & & & & $>0.99$ \\
\hline Yes & $3(5)$ & $1(7)$ & $2(4)$ & \\
\hline No & $57(95)$ & $14(93)$ & $43(96)$ & \\
\hline $\mathrm{SDH}(\%)$ & & & & $>0.99$ \\
\hline Yes & $42(70)$ & $11(73)$ & $31(69)$ & \\
\hline No & $18(30)$ & $4(27)$ & $14(31)$ & \\
\hline Cisterns (\%) & & & & 0.18 \\
\hline Absent & $11(18)$ & $2(13)$ & $9(20)$ & \\
\hline Compressed & $36(60)$ & $12(80)$ & $24(53)$ & \\
\hline Present & $13(22)$ & $1(7)$ & $12(27)$ & \\
\hline Midline shift (\%) & & & & 0.35 \\
\hline None & $13(22)$ & $4(27)$ & $9(20)$ & \\
\hline$<5 \mathrm{~mm}$ & $13(22)$ & $1(7)$ & $12(27)$ & \\
\hline $5-15 \mathrm{~mm}$ & $25(42)$ & $8(53)$ & $17(38)$ & \\
\hline$>15 \mathrm{~mm}$ & $9(15)$ & $2(13)$ & $7(16)$ & \\
\hline Decompressive surgery (\%) & & & & 0.35 \\
\hline Bilateral FTP & $7(12)$ & $3(20)$ & $4(9)$ & \\
\hline Unilateral FTP & $46(77)$ & $12(80)$ & $34(76)$ & \\
\hline Bifrontal & $7(12)$ & $0(0)$ & $7(16)$ & \\
\hline Type of decompressive surgery (\%) & & & & 0.67 \\
\hline Primary (<24 hrs) & $53(88)$ & $14(93)$ & $39(87)$ & \\
\hline Secondary (>24 hrs) & $7(12)$ & $1(7)$ & $6(13)$ & \\
\hline Postop meningitis (\%) & & & & 0.09 \\
\hline Yes & $5(8)$ & $3(20)$ & $2(4)$ & \\
\hline No & $55(92)$ & $12(80)$ & $43(96)$ & \\
\hline \multicolumn{5}{|l|}{ Postop imaging (\%) } \\
\hline Subdural hygroma & & & & $0.06 \dagger$ \\
\hline Bilateral & $7(12)$ & $4(27)$ & $3(7)$ & \\
\hline Unilateral & $31(52)$ & $11(73)$ & $20(44)$ & \\
\hline Ipsilateral & $26(84)$ & $8(73)$ & $18(90)$ & \\
\hline Contralateral & $5(16)$ & $3(27)$ & $2(10)$ & \\
\hline None & $22(37)$ & $0(0)$ & $22(49)$ & \\
\hline Interhemispheric hygroma (\%) & & & & $<0.001$ \\
\hline Yes & $19(32)$ & $11(73)$ & $8(18)$ & \\
\hline No & $41(68)$ & $4(27)$ & $37(82)$ & \\
\hline Modified Frontal Horn Index $\geq 33 \%$ (\%) & & & & 0.07 \\
\hline Yes & $26(43)$ & $10(67)$ & $16(36)$ & \\
\hline No & $34(57)$ & $5(33)$ & $29(64)$ & \\
\hline
\end{tabular}

FTP = fronto-temporo-parietal craniectomy; SDH = subdural hematoma.

Values are presented as the number of patients (\%) unless otherwise indicated.

* At admission to the emergency room.

$\dagger$ Comparison between bilateral and unilateral subdural hygroma. 
TABLE 2. Outcome data for patients undergoing DC after severe TBI categorized by shunt status

\begin{tabular}{|c|c|c|c|c|}
\hline \multirow[b]{2}{*}{ Outcome } & \multirow{2}{*}{$\begin{array}{l}\text { Total } \\
(\%)\end{array}$} & \multicolumn{2}{|c|}{$\begin{array}{c}\text { VPS Placement After } \\
\text { DC (\%) }\end{array}$} & \multirow{2}{*}{$\begin{array}{c}\mathrm{p} \\
\text { Value }\end{array}$} \\
\hline & & Yes & No & \\
\hline \multicolumn{5}{|c|}{ 3-mo GOS score $(n=57)$} \\
\hline Favorable & $4(7.0)$ & $0(0)$ & $4(9.5)$ & 0.56 \\
\hline Unfavorable & $53(92.9)$ & $15(100)$ & $38(90.5)$ & \\
\hline \multicolumn{5}{|c|}{ 6-mo GOS score $(n=55)$} \\
\hline Favorable & $9(16.4)$ & $1(7.1)$ & $8(19.5)$ & 0.42 \\
\hline Unfavorable & $46(83.6)$ & $13(92.9)$ & $33(80.5)$ & \\
\hline \multicolumn{5}{|l|}{ Death $(n=60)$} \\
\hline Yes & $14(23.3)$ & $1(6.7)$ & $13(28.9)$ & 0.16 \\
\hline No & $46(76.7)$ & $14(93.3)$ & $32(71.1)$ & \\
\hline
\end{tabular}

GOS = Glasgow Outcome Scale.

a VPS. Many prior studies have investigated predictors of PTH, but have not specifically investigated predictors of shunt-dependent hydrocephalus as was done in this study. $3,12,14,16,18,22$ In the present study, younger patients were more likely to develop hydrocephalus requiring a VPS after DC. Low et al. ${ }^{16}$ found that younger age was associated with PTH, while others have shown a link between older age and PTH. ${ }^{11,22}$ Kan et al. ${ }^{13}$ found a high incidence $(40 \%)$ of PTH requiring a VPS in children undergoing DC. High-energy mechanisms of injury, higher compliance of brain tissue, ${ }^{15}$ and lack of cerebral atrophy could contribute to an increased risk of symptomatic hydrocephalus in younger patients after DC.

The etiology of hydrocephalus after DC has been evaluated in prior studies. Disruption of CSF drainage due to arachnoid adhesions in the basal cisterns, loss of pulsatile intracranial CSF dynamics, ${ }^{23}$ and impaired venous drainage into the sagittal sinus ${ }^{3}$ have been proposed as causative factors. De Bonis et al. ${ }^{3}$ reported a higher risk of hydrocephalus if the superior limit of craniectomy was $<2.5 \mathrm{~cm}$ from the midline. Although we did not have 3D reconstructed $\mathrm{CT}$ images to evaluate this finding, we did note that no patient with a bifrontal craniectomy required a VPS. In bifrontal craniectomies, we do not extend the bone flap posterior to the coronal suture, which limits exposure of arachnoid granulations and parasagittal draining veins to atmospheric pressure. Additionally, only 1 of 6 patients with a bifrontal craniectomy demonstrated a subdural hygroma on CT. These findings are further supported by the findings of Polin et al., ${ }^{19}$ who performed bifrontal craniectomies extending $3-5 \mathrm{~cm}$ posterior to the coronal suture and showed a $28.6 \%$ risk of shunt-dependent hydrocephalus.

The present study was limited by small sample size and retrospective analysis. Although we found no significant difference in 6-month Glasgow Outcome Scale scores between the 2 groups, long-term follow-up is needed to establish the morbidity associated with VPS. Two patients in this series required shunt revisions for overshunting, and we note that pressure gradients do change over time for some of these patients. The use of programmable shunts in this patient population may improve our management of
TABLE 3. Multiple logistic regression model after variable selection

\begin{tabular}{lcll}
\hline \multicolumn{1}{c}{ Variable } & OR & \multicolumn{1}{c}{$95 \% \mathrm{Cl}$} & $\mathrm{p} \mathrm{Value}$ \\
\hline Age & 0.78 & $0.66-0.94$ & $0.009^{*}$ \\
\hline Interhemispheric hygroma & 63.6 & $4.97-816.44$ & $0.001^{*}$ \\
\hline Meningitis & 9.92 & $0.48-203.07$ & 0.14 \\
\hline SAH & 0.89 & $0.07-11.4$ & 0.93 \\
\hline
\end{tabular}

${ }^{*} p<0.05$.

PTH, although this needs to be evaluated in future studies. Despite these limitations, we studied prospectively collected data in a homogenous data set and add to the limited literature available on shunting for PTH after DC for trauma.

\section{Conclusions}

The presence of interhemispheric subdural hygromas and younger age were associated with shunt-dependent hydrocephalus after DC in patients with severe TBI.

\section{Acknowledgments}

This study was supported by grant no. P01-NS38660 from the National Institute of Neurological Disorders and Stroke.

\section{References}

1. Aarabi B, Chesler D, Maulucci C, Blacklock T, Alexander $\mathrm{M}$ : Dynamics of subdural hygroma following decompressive craniectomy: a comparative study. Neurosurg Focus 26(6):E8, 2009

2. Choi I, Park HK, Chang JC, Cho SJ, Choi SK, Byun BJ: Clinical factors for the development of posttraumatic hydrocephalus after decompressive craniectomy. J Korean Neurosurg Soc 43:227-231, 2008

3. De Bonis P, Pompucci A, Mangiola A, Rigante L, Anile C: Post-traumatic hydrocephalus after decompressive craniectomy: an underestimated risk factor. J Neurotrauma 27:19651970,2010

4. De Bonis P, Sturiale CL, Anile C, Gaudino S, Mangiola A, Martucci M, et al: Decompressive craniectomy, interhemispheric hygroma and hydrocephalus: a timeline of events? Clin Neurol Neurosurg 115:1308-1312, 2013

5. Gudeman SK, Kishore PR, Becker DP, Lipper MH, Girevendulis AK, Jeffries BF, et al: Computed tomography in the evaluation of incidence and significance of post-traumatic hydrocephalus. Radiology 141:397-402, 1981

6. Guerra WK, Gaab MR, Dietz H, Mueller JU, Piek J, Fritsch MJ: Surgical decompression for traumatic brain swelling: indications and results. J Neurosurg 90:187-196, 1999

7. Honeybul S, Ho KM: Incidence and risk factors for posttraumatic hydrocephalus following decompressive craniectomy for intractable intracranial hypertension and evacuation of mass lesions. J Neurotrauma 29:1872-1878, 2012

8. Huang AP, Tu YK, Tsai YH, Chen YS, Hong WC, Yang CC, et al: Decompressive craniectomy as the primary surgical intervention for hemorrhagic contusion. J Neurotrauma 25:1347-1354, 2008

9. Huh PW, Yoo DS, Cho KS, Park CK, Kang SG, Park YS, et al: Diagnostic method for differentiating external hydrocephalus from simple subdural hygroma. J Neurosurg 105:65-70, 2006

10. Jiang JY, Xu W, Li WP, Xu WH, Zhang J, Bao YH, et al: 
Efficacy of standard trauma craniectomy for refractory intracranial hypertension with severe traumatic brain injury: a multicenter, prospective, randomized controlled study. J Neurotrauma 22:623-628, 2005

11. Jiao QF, Liu Z, Li S, Zhou LX, Li SZ, Tian W, et al: Influencing factors for posttraumatic hydrocephalus in patients suffering from severe traumatic brain injuries. Chin J Traumatol 10:159-162, 2007

12. Kaen A, Jimenez-Roldan L, Alday R, Gomez PA, Lagares A, Alén JF, et al: Interhemispheric hygroma after decompressive craniectomy: does it predict posttraumatic hydrocephalus? J Neurosurg 113:1287-1293, 2010

13. Kan P, Amini A, Hansen K, White GL Jr, Brockmeyer DL, Walker ML, et al: Outcomes after decompressive craniectomy for severe traumatic brain injury in children. J Neurosurg 105 (5 Suppl):337-342, 2006

14. Ki HJ, Lee HJ, Lee HJ, Yi JS, Yang JH, Lee IW: The risk factors for hydrocephalus and subdural hygroma after decompressive craniectomy in head injured patients. J Korean Neurosurg Soc 58:254-261, 2015

15. Kiening KL, Schoening W, Unterberg AW, Stover JF, Citerio G, Enblad P, et al: Assessment of the relationship between age and continuous intracranial compliance. Acta Neurochir Suppl 95:293-297, 2005

16. Low CY, Low YY, Lee KK, Chan SP, Ang BT: Post-traumatic hydrocephalus after ventricular shunt placement in a Singaporean neurosurgical unit. J Clin Neurosci 20:867-872, 2013

17. Marmarou A, Foda MA, Bandoh K, Yoshihara M, Yamamoto T, Tsuji O, et al: Posttraumatic ventriculomegaly: hydrocephalus or atrophy? A new approach for diagnosis using CSF dynamics. J Neurosurg 85:1026-1035, 1996

18. Poca MA, Sahuquillo J, Mataró M, Benejam B, Arikan F, Báguena M: Ventricular enlargement after moderate or severe head injury: a frequent and neglected problem. J Neurotrauma 22:1303-1310, 2005

19. Polin RS, Shaffrey ME, Bogaev CA, Tisdale N, Germanson T, Bocchicchio B, et al: Decompressive bifrontal craniectomy in the treatment of severe refractory posttraumatic cerebral edema. Neurosurgery 41:84-94, 1997

20. Robertson CS, Hannay HJ, Yamal JM, Gopinath S, Goodman JC, Tilley BC, et al: Effect of erythropoietin and transfusion threshold on neurological recovery after traumatic brain injury: a randomized clinical trial. JAMA 312:36-47, 2014
21. Stiver SI: Complications of decompressive craniectomy for traumatic brain injury. Neurosurg Focus 26(6):E7, 2009

22. Tian HL, Xu T, Hu J, Cui YH, Chen H, Zhou LF: Risk factors related to hydrocephalus after traumatic subarachnoid hemorrhage. Surg Neurol 69:241-246, 2008

23. Waziri A, Fusco D, Mayer SA, McKhann GM II, Connolly ES Jr: Postoperative hydrocephalus in patients undergoing decompressive hemicraniectomy for ischemic or hemorrhagic stroke. Neurosurgery 61:489-494, 2007

24. Yang XF, Wen L, Shen F, Li G, Lou R, Liu WG, et al: Surgical complications secondary to decompressive craniectomy in patients with a head injury: a series of 108 consecutive cases. Acta Neurochir (Wien) 150:1241-1248, 2008

\section{Disclosures}

The authors report no conflict of interest concerning the materials or methods used in this study or the findings specified in this paper.

\section{Author Contributions}

Conception and design: Gopinath, Vedantam, Robertson. Acquisition of data: Vedantam, Robertson. Analysis and interpretation of data: all authors. Drafting the article: Vedantam, Robertson. Critically revising the article: Gopinath, Vedantam, Yamal, Robertson. Reviewed submitted version of manuscript: all authors. Approved the final version of the manuscript on behalf of all authors: Gopinath. Statistical analysis: Vedantam, Yamal, Hwang. Administrative/technical/material support: Gopinath, Robertson. Study supervision: Gopinath, Robertson.

\section{Supplemental Information Previous Presentations}

Portions of this work were presented as an abstract at the 2017 AANS Annual Meeting in Los Angeles, California, April 22-26.

\section{Correspondence}

Shankar P. Gopinath, Department of Neurosurgery, Baylor College of Medicine, 7200 Cambridge, Ste. 9A, MS: BCM650, Houston, TX 77030. email: shankarg@bcm.tmc.edu. 